\title{
Co-production of contaminated landscapes: anthropogenic loading and food web structure drive mercury bioaccumulation in abandoned gold mines
}

Jimena Diaz Leiva ( $\square$ jimena_diaz@berkeley.edu )

University of California, Berkeley https://orcid.org/0000-0001-5859-3134

Albert Ruhi

University of California, Berkeley

Matthew Potts

University of California, Berkeley

\section{Article}

Keywords: Artisanal and small-scale gold mining, bioaccumulation, biomagnification, food webs, coproduction

Posted Date: October 28th, 2020

DOl: https://doi.org/10.21203/rs.3.rs-88333/v1

License: (c) (i) This work is licensed under a Creative Commons Attribution 4.0 International License. Read Full License 


\section{Title Page}

Co-production of contaminated landscapes: anthropogenic loading and food web structure drive mercury bioaccumulation in abandoned gold mines

Jimena Diaz Leiva ${ }^{\mathrm{a}}$, Albert Ruhi ${ }^{\mathrm{a}}$, Matthew D. Potts ${ }^{\mathrm{a}}$

a. Department of Environmental Science, Policy, and Management, University of California, Berkeley. Mulford Hall, Berkeley, CA 94720.

Corresponding Author: Jimena Diaz Leiva

Email: jimena_diaz@berkeley.edu

This PDF file includes:

Main Text

Figures 1 to 4

Tables 1 to 2 


\section{Abstract}

2

3 Artisanal and small-scale mining is a significant and growing livelihood across the global South,

4 which all too often leaves a legacy of contaminated landscapes. Given the increasing reliance of

5 economies on metals and minerals, it is critical to understand what controls contamination

6 outcomes in this rapidly developing extractive practice. Here, we demonstrate that the emerging

7 concept of co-production offers a novel way to elucidate the joint contributions of natural and

8 societal factors in shaping contaminant exposure from artisanal and small-scale mining.

9 Specifically, understanding the co-production of contaminated landscapes requires attention to

10 both the political economy of mining, including how labor and extraction methods differ across

11 mines, as well as the sources and pathways of mercury exposure. In Madre de Dios, Peru, we

12 measured mercury levels in wildlife inhabiting abandoned gold mining sites worked with

13 different extraction technologies. We found that the type of technology used, whether heavy

14 machinery or suction-pump based, influenced mercury loading into mines, and together with

15 differences in food-web structure, mediated mercury biomagnification rates. Mercury

16 concentration increased 2.1 to 3.7 -fold per trophic level, and bioaccumulation levels were high in

17 both mined and unmined sites - indicating elevated background levels in the region. We also

18 found evidence of lateral transfer of mercury from abandoned mining pits to terrestrial food webs.

19 This observation indicates that the footprint of mercury contamination extends well beyond

20 individual mines, affecting the larger landscape. Our findings underscore the necessity of

21 understanding the entangled ways in which social and ecological factors contribute to the

22 production of toxic landscapes.

\section{Keywords}

24 Artisanal and small-scale gold mining, bioaccumulation, biomagnification, food webs, co-

25 production 


\section{Main Text \\ Introduction}

Artisanal and small-scale mining (ASM) is a complex, entangled social-natural system. Across the global South, ASM currently underpins the well-being of over 200 million people (1, 2), many of whom work under dangerous conditions to extract precious metals, gems, and other non-renewables (3). However, like most mining, ASM leaves a legacy of contaminated landscapes and sick people (4). Mining often causes the degradation of land, rendering it unusable for subsistence activities; all the while toxic elements used in extraction can cause serious health problems for individuals that consume contaminated food (5-9). We contend that understanding and addressing the environmental and social problems caused by ASM requires acknowledging that toxicity is co-produced by social and natural processes. This approach needs to integrate environmental sources and pathways of contaminant exposure, differences in labor relations and technologies used in ASM, and the ties between global resource politics and local resource extraction.

The case of artisanal and small-scale gold mining (AGSM) is particularly noteworthy because of the pronounced social and ecological changes brought on by the rapid expansion of ASGM throughout the global South. ASGM is a form of gold extraction characterized by the use of simple technologies such as repurposed car motors and suction pumps. ASGM largely occurs outside of formal economies and represents the principal livelihood for approximately 40 million workers and 150 million indirect beneficiaries - supplying more than $20 \%$ of global annual gold production $(1,2)$. While the livelihood benefits of ASGM are extensive, especially in underdeveloped rural communities (10), we still have a limited understanding of its full range of social and ecological impacts. 
52 inorganic mercury into the atmosphere, which can be redeposited in nearby waterbodies. In the

53 bottom sediments of these waterbodies, under certain abiotic conditions, inorganic mercury can

54 undergo a microbially-mediated transformation into methylmercury, the most toxic and

55 biologically available form of mercury (13-15). Many studies have documented bioaccumulation

56 of mercury in the vicinity of active mines (16-19), in sediments and tailings downstream of

57 mining (20-22), and even legacy contamination from mines that have long been abandoned (23,

58 24). Bioaccumulation of mercury can cause a wide range of detrimental impacts to wildlife such

59 as a reduction in growth (25-27), juvenile survivorship (28), reproductive success $(29,30)$, and

60 even mortality (31). Contaminant exposure extends beyond wildlife, as humans are also exposed

61 to mercury through the consumption of fish and other top predators (6). Because ASGM is

62 concentrated in culturally and biologically diverse areas of the globe (7), currently occurring in

63 more than 80 countries in the global South $(1,2)$, understanding risk of contaminant exposure in

64 these unique ecosystems is critical.

The emerging concept of co-production $(32,33)$ represents a novel way to conceptualize

66 the joint contributions of natural and societal factors in determining the risk from exposure to

67 contaminants from ASGM. Co-production of ecosystem services (or disservices) is the process by

68 which societies leverage labor, artefacts, and technology to use material and non-material flows

69 of nature to produce goods and services that benefit (or harm) humanity (34). For example,

70 hydropower is an ecosystem service co-produced by using built infrastructure (i.e., dams) to

71 harness river flow regimes - but dam-induced habitat fragmentation and altered flows represent

72 disservices that exact a high environmental cost $(35,36)$. Another example of co-production is

73 gold mining, wherein humans transform the natural wealth of geologic deposits into commodities

74 by using extractive technologies to remove, process, and refine auriferous rock. Just as the 
75 number and spatial arrangement of dams in a river network mediates the amount of harm done to

76 salmonid fisheries due to habitat fragmentation, the intensity and scale of mining impact the

77 conditions of a landscape and its ability to support bacterial production of toxic methylmercury.

78 Such place-specific nuances of ASGM underscore the need to improve our mechanistic

79 understanding of how co-production of contaminated landscapes is mediated by differences in the

80 political economy of gold production and the local ecological context.

81 The case of the bioaccumulation and biomagnification of mercury in wildlife inhabiting

82 abandoned gold mines in Madre de Dios, Peru illustrates the potential of using a co-production

83 approach. In Madre de Dios, a diversity of gold extraction methods co-exist with differing levels

84 of mechanization ranging from non-mechanized artisanal operations to heavily mechanized

85 operations using front loaders and excavators. Mechanization drives variation in the degree of

86 environmental impact (37) and in daily production volume which is often directly correlated with

87 mercury usage. A legacy of the increasing mechanization of ASGM is the creation of networks of

88 abandoned mining pits that cover approximately $28 \%$ of the land area deforested due to mining,

89 or an area equivalent to $\sim 20,000$ ha (38). Over time, these ponds are colonized by invertebrates,

90 fish, and other wildlife forming new networks of aquatic habitat. Many of these abandoned mines

91 also become sources of wild fish for people inhabiting nearby areas. However, these ponds are

92 also potential hotspots where inorganic mercury can be transformed into methylmercury, and

93 bioaccumulate in wildlife $(24,39)$. In Madre de Dios, there is growing evidence that mercury

94 contamination from ASGM extends beyond the boundaries of mining areas as high levels of total

95 inorganic mercury $(\mathrm{THg})$ have been documented in downstream river sediments $(21,22)$, fish

96 (16), indigenous populations upstream of mining (40), and in wildlife found far from mining areas

97 (19). 
Here we examined how co-production of contaminated landscapes mediated exposure

99 risk to wildlife in three distinct ways. First, we evaluated whether mercury bioaccumulation in

100 wildlife inhabiting abandoned gold mines differed when compared to mercury concentrations in

101 wildlife found in unmined sites. We found that bioaccumulation was high in all sites, even

102 unmined sites, but that bioaccumulation in wildlife was highest in those sites where ASGM

103 occurred

Second, we evaluated whether extraction technologies influenced mercury

105

biomagnification rates by comparing natural lakes in an unmined watershed to areas worked with heavy machinery (HM) and those worked with suction-pump based techniques (SP). We

107 estimated the trophic magnification slope (TMS) by regressing THg concentrations against stable

108 nitrogen isotopes $(\delta 15 \mathrm{~N})$ of multiple consumers common to all mining pits. Our estimated TMS

109 of $0.46 \pm 0.03$ was on the high end of reported values for tropical freshwater, lentic environments.

110 Further, we found that the type of technology used in gold production influenced the degree of

111 mercury loading (as measured by sediment THg concentration), and together with differences in

112 food-web structure across abandoned mines, these factors controlled the rate of mercury

113 biomagnification at each site.

Finally, we determined whether mining pits subsidize mercury for terrestrial ecosystems

115 via export of contaminated prey that are then consumed by riparian predators. We collected a

116 riparian predator common to all sites, long-jawed orb-weaving spiders (Family: Tetragnathidae)

117 and compared $\mathrm{THg}$ concentration and trophic position of these spiders to those of aquatic

118 consumers. We confirmed that cross-ecosystem subsidies of aquatic prey transfer not only energy

119 but also contaminants to riparian and terrestrial food webs. This result confirms that the footprint

120 of mercury contamination extends beyond boundaries of individual mining pits, further exposing

121 humans and wildlife. 


\section{Results}

We found high levels of mercury bioaccumulation and biomagnification in taxa sampled across all mined and unmined sites (Fig. 2b, and SI Appendix, Table S1). However, the highest mercury concentrations were found in wildlife collected in abandoned gold mines as compared to unmined sites (Table S1). Taxonomic groups showed relatively consistent trophic positions across sites (as measured by $\delta 15 \mathrm{~N}$ ), but spanned $>2$ trophic levels from snails (caenogastropoda), lowest in the food chain, to piranha (Serrasalmus spp.) and wolf fish (Hoplias malabaricus), apical predators (Fig. 2a). Accordingly, predatory fishes contained the highest average concentrations of THg (Fig. 2b). We also found strong evidence of biomagnification. Total inorganic mercury concentrations $(\mathrm{THg}$ ) were significantly and positively correlated with estimated trophic position $(\delta 15 \mathrm{~N})$ across all sites $\left(\mathrm{R}^{2}=0.61, p<0.0001\right)$. The rate of mercury biomagnification represented by the average trophic magnification slope (TMS) calculated from the linear regression of $\log _{10}$-transformed total mercury concentrations against trophic position $(\delta 15 \mathrm{~N} \%$ \%) was $0.46 \pm 0.03(p<0.0001, \mathrm{n}=115$, Fig. 3$)$. Back-transformed, this TMS slope is equivalent to a 2.7 to 3.1 -fold increase in mercury concentration with each trophic transfer. Given that TMS $>0$, these data indicate that THg is being biomagnified through aquatic food chains in mining pits and unmined, natural oxbow lakes.

Beyond differences in bioaccumulation and biomagnification between unmined and mined sites, we found evidence of co-production of contamination: THg loading was influenced by both social and natural factors (Table 1). To fully parse the relative importance of trophic position, THg loading in sediments, and the effect of extraction technology on bioaccumulation of mercury in biota, we compared fits of different explanatory model structures. Specifically, we compared support across four linear mixed-effect models using an information-theoretic approach via BIC (Table 1). We found that including an interaction effect between organism trophic 
148 position and extraction technology (i.e., whether the site was worked with HM, SP, or was an

149 unmined site) greatly improved model fit over a restricted model that included the effects of

150 technology and trophic position separately. We also evaluated the two best fit models using log-

151 likelihood tests (Table 1, models $3 \& 4$ ). We found that model 4, which included the interaction

152 effect as well as the fixed effect of mercury loading (THgSed), was significantly different from

153 model $3\left(\chi^{2}(1)=5.806, p=0.016\right)$. This finding suggests that mercury loading, influenced by the

154 type of extraction technology used, drives patterns in mercury bioaccumulation across a diversity 155 of taxonomic groups.

156
In addition, we found that sediment total mercury concentration (THgSed), a proxy for mercury loading to each mining pit or reference lake system, varied across sites worked with different technologies (Fig. 3, SI Appendix, Fig. S1) with a significant difference in mean total mercury concentration across site types $\left(\mathrm{F}_{2,36}=3.438, p=0.043\right)$. The highest levels of loadings were recorded in pits worked by suction pumps, followed by pits worked by HM, and then unmined oxbow lakes. A post-hoc Tukey HSD analysis indicates that sites worked with suction pump machinery were significantly different in $\mathrm{THgSed}$ concentrations than those in unmined sites. There was no difference in THgSed between unmined sites and heavy machinery sites. However, we found that one of the oxbow lakes in our control sites was elevated in $\mathrm{THgSed}$ possibly due to the fact that this lake is a palm swamp with low concentrations of dissolved oxygen (SI Appendix, Table S2). If this lake were excluded from the analysis, then the mean THgSed would be significantly different between all paired comparisons of sites.

Finally, we found evidence of lateral transfer of mercury from abandoned mining pits to terrestrial, riparian consumers (Fig. 4). Stable isotopes of $\delta 15 \mathrm{~N}$ as well as field observations of feeding behavior, confirm that a riparian predator, long-jawed orb weaving spiders, consume 
173 aquatic prey, acting as recipients of mercury subsidies from abandoned mining pits. These

174 riparian consumers bioaccumulated mercury at concentrations that fell within those predicted by

175 the relationship between THg concentrations and trophic position of our aquatic taxa.

176

177

178

179

180

181

182

183

\section{Discussion}

Co-production drives mercury accumulation and biomagnification in AGSM sites

We found strong novel evidence that mercury contamination in Madre de Dios, Peru, is co-produced by social and natural processes. Both mercury bioaccumulation levels and biomagnification rates were driven by variation in mining practices and differences in food-web structure. Participant observation and interviews with miners by JDL confirm that different methods of gold extraction influenced the degree of mercury loading into mining sites. Where heavy machinery-based mining (HM) occurs, there is never direct amalgamation in mining pits and thus little or no input of elemental mercury from tailings [Diaz Leiva, 2020, in prep]. Instead, these HM pits are constructed as water storage ponds and are filled-in by groundwater infiltration. Water is pumped out of the ponds to constructed sluice boxes sometimes more than 200 meters away to wash auriferous material that is brought from elsewhere on-site. Therefore, the method of gold extraction, whether using HM or SP technologies plays an important role in directly mediating the quantity and location of mercury discharges on the landscape. Our finding adds evidence to the argument that local or regional-level differences in ASGM practices may affect mercury loading into aquatic ecosystems (41).

$$
\text { as estimated by subtracting trophic position of the top consumer from the primary consumers), }
$$
which is known to affect biomagnification rates, varied by sites worked with different extraction technologies. In pits worked with heavy machinery, the average FCL was 2.70, for SP pits it was 
2.30, and for reference lakes it was 2.05. While we do not know the mechanism driving differences in FCL across sites worked with different technologies, we postulate that differences in feeding behavior of the same organism across sites (i.e., omnivory in predatory fish) or food web complexity (i.e., addition or insertion of top consumers lengthening the food chain) may be responsible for this variation (42). Understanding the exact mechanism is particularly important

205 given that wildlife in these landlocked ponds will readily bioaccumulate contaminants from 206 dietary exposure and differences in FCL will mediate the accumulation of contaminants at the top 207 of the food chain. However, trophic position alone did not explain variation in bioaccumulation of $208 \mathrm{THg}$ in wildlife across sites, as taxa with the same trophic position (e.g., Hypostomus spp., 209 Serrasalmus spp.) were consistently higher in $\mathrm{THg}$ concentration in SP pits relative to HM pits.

210 Only when we took the full suite of co-production factors - trophic position, extraction

211 technology, and mercury loading - into account did our model (Table 1) best explain the patterns

212 in bioaccumulation and biomagnification we observed across sites.

213

\section{Diffuse Mercury Contamination in Madre de Dios}

We found extremely high mercury biomagnification rates in our study sites. Our estimated TMS $(0.46 \pm 0.03)$ is more than three times that of the mean global value for freshwater tropical sites, $0.12 \pm 0.12(43)$, and at the high end for studies restricted to Amazonia, which ranged from $0.21-0.43(44-49)$. These magnification rates have led to levels of top-predator mercury bioaccumulation that represent a significant public and environmental health risk. Predatory fish species (H. malabaricus and Serrasalmus spp.) caught in both unmined natural lakes and abandoned mines contained concentrations of mercury that exceeded international consumption limits by two to five times on average. Our findings are consistent with previous measurements of bioaccumulation in H. malabaricus in oxbow lakes in the Bolivian Amazon (46). The highest levels of bioaccumulation were recorded in predatory fish caught in abandoned 
225 mines worked with suction-pump based technologies. The concentration of THg in two piranha

226 (Serrasalmus spp.) was 26.7 and $26.1 \mathrm{mg} / \mathrm{kg}$ respectively, more than 50 times the European

227 Union's recommended consumption limit of $0.5 \mathrm{mg} / \mathrm{kg}$. These values are similar to those reported

228 in highly contaminated spill sites (50).

229

Perhaps most concerning, we found consistently high concentrations of $\mathrm{THg}$ in higher

231 trophic-level organisms - irrespective of presumed differences in mercury loading across

232 abandoned mining pits and unimpacted oxbow lakes. This result suggests that the

233 bioaccumulation potential of organisms inhabiting lentic environments in this region is high.

234 Importantly, our reference sites were located in a densely forested, protected watershed far from

235 direct elemental mercury inputs. Future research should focus on understanding the sources of

236 this mercury and quantifying the methylation potential of ponds and oxbow lakes to parse apart

237 why there are such elevated background levels in Madre de Dios. Researchers should leverage

238 environmental tracers such as mercury stable isotopes to determine whether these high

239 background levels bear the signature of mercury used in ASGM or whether these high levels are

240 due to the release of mercury from natural sources such as soil erosion(51). This question

241 remains unresolved in the literature as some studies have found that the signature of mercury in

242 sediments collected downstream of ASGM does not belong to mercury used in these operations

243 but is instead from mercury released from soils and trees due to deforestation from mining and

244 other land uses (41-43).

245

246

\section{Cross-Ecosystem Transfer of Mercury Extends the Footprint of Contamination}

Beyond high background levels, our findings indicate that networks of abandoned gold

248 mining pits may act as hotspots of biomagnification in landscapes impacted by informal gold

249 mining. Given that long jawed orb weaving spiders are consumed by mobile predators such as 
bats and are not the only terrestrial consumers of emergent aquatic insects, we expect this

251 contaminant subsidy to propagate through food webs far beyond the riparian zone of abandoned

252 mining pits. Previous studies in the Amazon have found elevated levels of mercury in alluvial

253 sediments downstream of mining sites and soils taken from areas proximate to active mining, but

254 this study is the first to demonstrate that abandoned mining pits are an important source of

255 mercury to the terrestrial biota inhabiting these highly impacted systems. More work is needed to

256 fully understand the risk of contaminant exposure to higher trophic levels organisms. Previous

257 work suggests that the degree to which these mining pits export mercury via emergent aquatic

258 insects depends on the life history of these insects, as metamorphosis of aquatic larvae into adults

259 reduces heavy metal burden in aquatic predators such as dragonflies and consequent

260 accumulation in cross-system predators (52). In addition, body size of emergent aquatic insects,

261 mediated by top-down interactions, can also alter contaminant flux into terrestrial ecosystems

262 (53). In addition, these mosaics of abandoned mining pits form new habitat for migratory birds

263 and other higher trophic levels organisms whose mobility allows them to further extend the

264 footprint of mercury contamination from ASGM.

While these pits can act as sources of methylmercury to wildlife, it should be noted that

267 these results also indicate that there is high heterogeneity in mercury bioaccumulation and

268 biomagnification potential within abandoned gold mining landscapes driven largely by the

269 differences in the political economy of ASGM. The diversity in mining operations drive variation

270 in quantity and location of mercury discharges such that not everywhere in a mined landscape

271 will there be evidence of high levels of mercury in biota. In turn, areas far removed from gold

272 mining could have high levels of mercury in wildlife due to cross-ecosystem subsidies and

273 mobility of consumers. Thus, sampling only one compartment such as the sediment of mining pits

274 or the soils around abandoned mines can lead to inconclusive results, as differences in mercury 
275 bioaccumulation higher up in the food chain are not apparent from the relatively small differences

276 in mercury loading in sediment (on the order of $10 \mathrm{ng}$ ). Further, proposals to utilize these

277 contaminated landscapes for production of fish through aquaculture or for farming should take

278 into account the type of technology that was used in gold production(38). Sites worked with HM

279 may be safer candidates for remediation for aquaculture than sites worked SP. Additionally, top

280 consumers like predatory fish, fish-eating birds, and mammals should be closely monitored due to

281 their susceptibility to accumulate mercury especially from sites where SP technologies were used.

282

283 Conclusion

284 Environmental contamination is not an isolated or unique phenomenon, but instead it is 285 part of a ubiquitous pattern that implicates human's continued consumption of resources in the 286 degradation of the natural world (54). Our globalized economy's reliance on non-renewable 287 resources is unlikely to diminish in the near future, especially with the use of precious metals in 288 climate-change mitigating technologies like solar panels and electric car batteries (55-57). To

289 have any hope of mitigating the worst effects of contaminant exposure or remediating already

290 contaminated landscapes, we must understand the entangled ways in which social and ecological

291 factors contribute to the production of toxic landscapes. A co-production approach, that explicitly

292 incorporates the social and natural, can help guide the kind of studies that are urgently needed to

293 ensure that our planet continues to provide the life supporting services that we depend on while

294 also ensuring just outcomes for those people who depend on resource extraction for their

295 livelihoods.

296

297

298

299 Study Site \& Field Sampling. We conducted our study in the Department of Madre de Dios,

300 Peru, a region located at the western edge of the Amazon basin (Fig. 1). We sampled across four 
sites, with each site characterized by the use of either suction-pump (SP) or heavy machinery

302 (HM) extraction technologies as well as one unmined site. On the surface, the mining pits created

303 by these two different mining technologies appear similar, however they differ in key aspects.

304 Suction pump-based technologies create mining pits that are more heterogeneous in their

305 bathymetric profile and on average much deeper than their counterparts created with heavy

306 machinery. The volume of gold-bearing alluvium processed daily by these two types of

307 production also differs. Daily production volume is approximately proportional to the level of

308 mechanization and subsequently influences the amount of mercury used in amalgamation of gold

309 at the end of a day's shift.

311 To test whether production practices mediate mercury biomagnification, we sampled multiple

312 abandoned gold mining pits $(\geq 2)$ at each site. A total of 10 mining pits were sampled including

313 seven mining pits where SP technologies were used and three mining pits where HM was used.

314 We were unable to access more sites worked with HM due to the rapidly changing security

315 threats posed by a state of emergency declared in the region. At the unmined site, we assessed

316 background biomagnification rates in four natural oxbow lakes located along a river in a

317 protected watershed unimpacted by gold mining. Mining pits resembled artificial ponds and many

318 contained floating and emergent macrophytes including Paspalum repens, Hymenache spp., as

319 well as a diversity of fauna. Pits ranged in size from 0.3 ha to $\sim 4$ ha and varied in bathymetric

320 profile based on the type of technology used in gold production. The average depth of pits

321 worked with SP was $2.48 \mathrm{~m}$ and $1.75 \mathrm{~m}$ for pits worked with HM.

322 To estimate the rate of biomagnification across sites, we sampled for the same taxa across all pits

323 and oxbow lakes including benthic macroinvertebrates and algivorous and piscivorous fish.

324 Benthic macroinvertebrates common across all pits and oxbow lakes included predatory

325 dragonflies (Families: Gomphidae, Libellulidae), giant water bugs (Family: Belostomatidae), and 
water scorpions (Family: Nepidae). Primary consumer invertebrates (herbivorous/detritivorous

327 strategies) included (Family: Caenogastropoda) and burrowing mayflies (Family:

328 Polymitarcyidae). Benthic macroinvertebrates were live sorted to family level and then kept in

329 water for 12-24 hours to clear gut contents. In the lab, the invertebrates were counted, measured

330 and pooled by family to produce a composite sample for each pit. The invertebrates were kept

331 frozen until they were freeze-dried at $-56^{\circ} \mathrm{C}$ for 72 hours. Gastropods were used for estimation of

332 baseline $\delta^{15} \mathrm{~N}$ following Post $(2002,58)$. In addition, a maximum of three individuals of the

333 following fish species were collected at each mining pit or oxbow lake; piranha (Serrasalmus

334 spp.), wolf fish (Hoplias malabaricus), and armored catfish (Hypostomus spp.). Fish were

335 collected using a gill net deployed on the same day as invertebrate collection; length and weight

336 were measured, and dorsal muscle tissues were removed, placed on ice until they could be frozen,

337 and later freeze-dried.

339 To determine whether riparian consumers of emergent aquatic insects bioaccumulate mercury

340 from aquatic resource subsidies, we collected long jawed orb-weaving spiders (Family:

341 Tetragnathidae) from the vegetation at the margins of each pit and lake. Many studies have shown

342 that in temperate zones, long-jawed orb-weaving spiders (Family: Tetragnathidae) and other

343 riparian consumers feed on emergent insects that accumulate mercury and other contaminants

344 during their aquatic larval phase (59-62). Hand collection of spiders occurred on the same day as

345 collection of fish and benthic macroinvertebrates. Spiders were counted, frozen on ice and later

346 freeze-dried at $-56^{\circ} \mathrm{C}$ for 72 hours.

348 To estimate mercury loading in each pit or lake, surface sediment samples were collected in 349 triplicate using an Ekman dredge and analyzed for total mercury content. Samples for water 
chemistry were also collected in situ at each point where a sediment sample was taken using a multiparameter Hanna HI91894. All sampling was conducted during the dry season from April-

352 August 2019.

354 Research protocol and methodologies for handling fish specimens were approved by UC

355 Berkeley's Animal Care and Use Committee (\#AUP-2018-06-11147).

Laboratory Analyses. Laboratory processing and analysis followed similar procedures to Wyn et 358 al. $(2014,63)$. Individual fish muscle samples and invertebrate samples (pooled with greater than 3595 individuals per taxon) were freeze-dried, homogenized, and subsampled once for each analysis. 360 Approximately $20 \mathrm{mg}( \pm 10 \mathrm{mg})$ of homogenized fish muscle or whole macroinvertebrate 361 composite was analyzed on a Milestone DMA-80 direct mercury analyzer (Milestone Inc., Shelton, 362 CT, USA) at the Carnegie Institute for Global Ecology at Stanford University (Stanford, California, 363 USA). Samples of certified reference material (DORM4 or TILL3) were within acceptable recovery 364 limits. All Hg data are expressed on a dry weight basis. Duplicate analytic measurements were 365 analyzed for each fish, invertebrate, and sediment sample analyzed for $\mathrm{THg}$, and the two results were averaged for the reported result. The average relative percent difference in $\mathrm{THg}$ measurements 367 of duplicate samples was $1.1 \%$. Quality control measures included testing of standard reference 368 materials and internal laboratory standards. Continuing calibration verification and continuing 369 calibration blank measurements were determined on every tenth sample analyzed in accordance 370 with US EPA Method 7473 (64). The Method Detection Limit for total Hg analysis is $2 \mathrm{ng} / \mathrm{g}$. No 371 fish, invertebrate, or sediment samples were rejected based on quality control results or duplicate 372 relative percent differences. Additional information on QA/QC of samples can be found in 373 supplemental materials (SI Appendix). 
375 Samples were analyzed for $\delta^{15} \mathrm{~N}$ and $\delta^{13} \mathrm{C}$ at the Center for Stable Isotope Biogeochemistry at the

376 University of California, Berkeley (Berkeley, California, USA). Stable isotope composition is

377 expressed in parts per thousand as a deviation from a standard reference material. Nitrogen

378 isotopic values were standardized against $\mathrm{N}_{2}$ gas in air as follows:

$379 \quad \delta 15 N=\left(\left(R_{\text {sample }} \div R_{\text {standard }}\right)-1\right) * 1000$

380 Stable nitrogen isotopes were used to approximate the relative trophic position of an organism

381 because the relative abundance of ${ }^{15} \mathrm{~N}$ in proportion to ${ }^{14} \mathrm{~N}$ in a consumer is enriched by an

382 estimated 3-4\%o per trophic level $(58,65-69)$. The trophic level of an organism can then be

383 adjusted by measuring $\delta^{15} \mathrm{~N}$ in a primary consumer such as algivorous freshwater snails and

384 correcting $\delta^{15} \mathrm{~N}$ of higher-level consumers as in the following equation:

385

$386 T L_{\text {consumer }}=\frac{\delta 15 N_{\text {consumer }}-\delta 15_{\text {primary consumer }}}{\Delta 15 N}+\lambda$

387

388 Where $\Delta^{15} \mathrm{~N}$ is one of the most common enrichment factors used in studies of aquatic food webs,

$3.4 \%$ (this however is not the only enrichment factor used in studies) and $\lambda$ is the trophic level of

the baseline primary consumer $(\mathrm{TL}=2)$. Additional information on QA/QC of samples can be

391 found in supplemental materials (SI Appendix).

392

393 Data Analyses. To test for differences in the biomagnification rate across sites worked with

394 different extraction technologies, we used tests of analysis of covariance (ANCOVA; R Version

395 3.6.1) (70). Trophic position (continuous independent variable) and technology (categorical

396 independent variable) on total mercury concentration in biota (THg; continuous dependent

397 variable). We tested for an interaction effect between technology and trophic position, which

398 would indicate that the slope estimate for the relationship between trophic position and mercury

399 concentration was dependent on the type of technology used. If the interaction effect was not

400 significant, we removed the term and assessed the main effects of trophic position and technology 
401 independently. We also tested for differences in mercury loading across pits worked with the 402 same technology using ANOVA and a post-hoc Tukey HSD test to evaluate whether there was a 403 difference in sediment mercury loading across sites. Finally, we used a generalized linear mixed 404 effects model, lme4 (lmer package, 71) to evaluate the proportion of variance in total mercury 405 concentration of biota that was explained by a model that accounted for the random effect of pits 406 nested within sites worked with different extraction technologies, as well as the fixed effects of 407 mercury loading as estimated by the average pit or lake sediment total mercury concentration 408 (THgSed), trophic position, and the interaction between trophic position and extraction 409 technology. We compared our models using Bayesian information criterion (BIC) scores and chi410 square log-likelihood ratio tests. 


\section{References}

1. G. Hilson, J. McQuilken, R. Perks, "State of the Artisanal and Small-Scale Mining Sector 2019" in DELVE, a Global Platform for Artisanal and Small-Scale Mining Data, (World Bank, Washington DC, 2019), pp. 1-98.

2. Intergovernmental Forum on Mining, Minerals, and Sustainable Development, "Global Trends in Artisanal and Small-Scale Mining (ASM): a Review of Key Numbers and Issues", (IISD, Winnipeg, Canada, 2017).

3. K. Lahiri-Dutt, "Reframing the debate on informal mining" in Between the Plough and the Pick: Informal, Artisanal and Small-Scale Mining in the Contemporary World, K. LahiriDutt, Ed. (ANU Press, 2018), pp. 1-28.

4. G. Hilson, Small-scale mining and its socio-economic impact in developing countries. Nat. Resour. Forum 26, 3-13 (2002).

5. H. Hsu-Kim, K. H. Kucharzyk, T. Zhang, M. A. Deshusses, Mechanisms regulating mercury bioavailability for methylating microorganisms in the aquatic environment: A critical review. Environ. Sci. Technol. 47, 2441-2456 (2013).

6. C. A. Eagles-Smith, et al., Modulators of mercury risk to wildlife and humans in the context of rapid global change. Ambio 47, 170-197 (2018).

7. N. L. Alvarez-Berríos, T. Mitchell Aide, Global demand for gold is another threat for tropical forests. Environ. Res. Lett. 10, 014006 (2015).

8. G. P. Asner, W. Llactayo, R. Tupayachi, E. R. Luna, Elevated rates of gold mining in the Amazon revealed through high-resolution monitoring. Proc. Natl. Acad. Sci. U. S. A.110, 18454-9 (2013).

9. G. P. Asner, R. Tupayachi, Accelerated losses of protected forests from gold mining in the Peruvian Amazon. Environ. Res. Lett. 12 (2017).

10. G. Hilson, J. McQuilken, Four decades of support for artisanal and small-scale mining in subSaharan Africa: A critical review. Extr. Ind. Soc. 1, 104-118 (2014).

11. UN Environment Programme, "Global Mercury Assessment 2018” (UNEP, Geneva, Switzerland, 2018).

12. M. M. Veiga, P. A. Maxson, L. D. Hylander, Origin and consumption of mercury in smallscale gold mining. J. Clean. Prod. 14, 436-447 (2006).

13. T. Barkay, I. Wagner-Dobler, "Microbial transformations of mercury: Potentials, challenges, and achievements in controlling mercury toxicity in the environment", in Advances in Applied Microbiology, A.I. Laskin, J.W. Bennett, and G.M., Eds. (Elsevier, 2005), pp. 1-52.

14. C. A. Eagles-Smith, et al., Mercury in western North America: A synthesis of environmental contamination, fluxes, bioaccumulation, and risk to fish and wildlife. Sci. Total Environ. 568, 1213-1226 (2016).

15. J. G. Wiener, Ecotoxicology of Mercury, A. M. Wiener, James G., Krabbenhoft, D.P., Heinz, G.H., Scheuhammer, Ed. (2003) https:/doi.org/10.1201/9781420032505.sec2.

16. G. Martinez, et al., Mercury contamination in riverine sediments and fish associated with artisanal and small-scale gold mining in Madre de Dios, Peru. Int. J. Environ. Res. Public Health 15, 1-15 (2018).

17. R. P. Mason, et al., An assessment of the impact of artisanal and commercial gold mining on mercury and methylmercury levels in the environment and fish in Cote d'Ivoire. Sci. Total Environ. 665, 1158-1167 (2019).

18. A. Palheta, Dulcideia, Taylor, Mercury in environmental and biological samples from a gold mining area in the Amazon region of Brazil. Sci. Total Environ., 63-69 (1995). 
19. M. Moreno-Brush, et al., Mercury concentrations in bats (Chiroptera) from a gold mining area in the Peruvian Amazon. Ecotoxicology 27, 45-54 (2018).

20. S. Nurfitriani, E. Arisoesilaningsih, Y. Nuraini, E. Handayanto, Bioaccumulation of mercury by bacteria isolated from small scale gold mining tailings in Lombok, Indonesia. J. Ecol. Eng. 21, $127-136$ (2020).

21. S. E. Diringer, et al., River transport of mercury from artisanal and small-scale gold mining and risks for dietary mercury exposure in Madre de Dios, Peru. Environ. Sci. Process. Impacts 17, 478-487(2015).

22. E. N. Dethier, S. L. Sartain, D. A. Lutz, Heightened levels and seasonal inversion of riverine suspended sediment in a tropical biodiversity hot spot due to artisanal gold mining. Proc. Natl. Acad. Sci. U. S. A. 116, 23936-23941 (2019).

23. B. D. Krisnayanti, et al., Assessment of environmental mercury discharge at a four-year-old artisanal gold mining area on Lombok Island, Indonesia. J. Environ. Monit. 14, 2598-2607 (2012).

24. M. M. Veiga, J. J. Hinton, Abandoned artisanal gold mines in the Brazilian Amazon: A legacy of mercury pollution. Nat. Resour. Forum 26, 15-26 (2002).

25. A. M. Scheuhammer, M. W. Meyer, M. B. Sandheinrich, M. W. Murray, Effects of environmental methylmercury on the health of wild birds, mammals, and fish. Ambio 36, 12 18 (2007).

26. M. C. Whitney, D. A. Cristol, "Impacts of Sublethal Mercury Exposure on Birds: A Detailed Review" in Reviews of Environmental Contamination and Toxicology Volume 244, P. de Voogt, Ed. (Springer International Publishing, 2018), pp. 113-163.

27. A. Houck, J. J. Cech, Effects of dietary methylmercury on juvenile Sacramento blackfish bioenergetics. Aquat. Toxicol. 69, 107-123 (2004).

28. D. C. Evers, et al., Adverse effects from environmental mercury loads on breeding common loons. Ecotoxicology 17, 69-81 (2008).

29. N. M. Burgess, M. W. Meyer, Methylmercury exposure associated with reduced productivity in common loons. Ecotoxicology 17, 83-91 (2008).

30. C. W. Varian-Ramos, J. P. Swaddle, D. A. Cristol, Mercury reduces avian reproductive success and imposes selection: An experimental study with adult- or lifetime-exposure in zebra finch. PLoS One 9 (2014).

31. C. M. Bergeron, W. A. Hopkins, B. D. Todd, M. J. Hepner, J. M. Unrine, Interactive effects of maternal and dietary mercury exposure have latent and lethal consequences for amphibian larvae. Environ. Sci. Technol. 45, 3781-3787 (2011).

32. S. Díaz, et al., The IPBES Conceptual Framework - connecting nature and people. Curr. Opin. Environ. Sustain. 14, 1-16 (2015).

33. S. Díaz, et al., Assessing nature's contributions to people. Science 359, 270-272 (2018).

34. I. Palomo, M. R. Felipe-Lucia, E. M. Bennett, B. Martín-López, U. Pascual, "Chapter Six Disentangling the Pathways and Effects of Ecosystem Service Co-Production" in Ecosystem Services: From Biodiversity to Society, Part 2, G. Woodward, D. A. B. T.-A. in E. R. Bohan, Eds. (Academic Press, 2016), pp. 245-283.

35. S. E. Bunn, A. H. Arthington, Basic principles and ecological consequences of altered flow regimes for aquatic biodiversity. Environ. Manage. 30, 492-507 (2002).

36. M. Palmer, A. Ruhi, Linkages between flow regime, biota, and ecosystem processes: Implications for river restoration. Science 365, (2019).

37. J. C. Espejo, M. Messinger, F. R. D, C. Ascorra, E. Luis, Deforestation and forest degradation due to gold mining in the Peruvian Amazon: a 34-year perspective. Remote Sens., 1-17 (2018). 
38. J.C. Espejo et al., "Conversion de Paisajes Forestales a Humedales Amazonicos por Mineria Aurifera" CINCIA Research Brief \#5, (2020). http://cincia.wfu.edu/en/wpcontent/uploads/CINCIA_research_brief_5_es.pdf

39. M. M. Chumchal, R. W. Drenner, An environmental problem hidden in plain sight? Small Human-made ponds, emergent insects, and mercury contamination of biota in the Great Plains. Environ. Toxicol. Chem. 34, 1197-1205 (2015).

40. L.E. Fernandez et al., Elevated mercury levels in recently contacted Amazonian indigenous communities in Peru may reveal an undescribed natural mercury hotspot that could represent a significant health risk to these populations, in $14^{\text {th }}$ International Conference on Mercury as a Global Pollutant, (2019) https:/doi.org/10.13140/RG.2.2.21694.84804.

41. G. Schudel, et al., An investigation of mercury sources in the Puyango-Tumbes River: Using stable $\mathrm{Hg}$ isotopes to characterize transboundary $\mathrm{Hg}$ pollution. Chemosphere 202, 777-787 (2018).

42. D. M. Post, G. Takimoto, Proximate structural mechanisms for variation in food-chain length. Oikos 116, 775-782 (2007).

43. P. J. Lechler, et al., Elevated mercury concentrations in soils, sediments, water, and fish of the Madeira River basin, Brazilian Amazon: A function of natural enrichments? Sci. Total Environ. 260, 87-96 (2000).

44. R. Adler Miserendino, et al., Challenges to measuring, monitoring, and addressing the cumulative impacts of artisanal and small-scale gold mining in Ecuador. Resour. Policy 38, 713-722 (2013).

45. R. A. Lavoie, T. D. Jardine, M. M. Chumchal, K. a Kidd, L. M. Campbell, Biomagnification of Mercury in Aquatic Food Webs: A Worldwide Meta-Analysis. Environ. Sci. Technol. 47, 13385-13394 (2013).

46. M. Pouilly, et al., Trophic Structure and Mercury Biomagnification in Tropical Fish Assemblages, Iténez River, Bolivia. PLoS One 8, (2013).

47. C. I. Molina, et al., Transfer of mercury and methylmercury along macroinvertebrate food chains in a floodplain lake of the Beni River, Bolivian Amazonia. Sci. Total Environ. 408, 3382-3391 (2010).

48. S. Y. Kwon, P. B. McIntyre, A. S. Flecker, L. M. Campbell, Mercury biomagnification in the food web of a neotropical stream. Sci. Total Environ. 417-418, 92-97 (2012).

49. C. E. Azevedo-Silva, et al., Mercury biomagnification and the trophic structure of the ichthyofauna from a remote lake in the Brazilian Amazon. Environ. Res. 151, 286-296 (2016).

50. A. G. Bravo, et al., Extremely elevated methyl mercury levels in water, sediment and organisms in a Romanian reservoir affected by release of mercury from a chlor-alkali plant. Water Res. 49, 391-405 (2013).

51. B. A. Bergquist, J. D. Blum, The odds and evens of mercury isotopes: Applications of massdependent and mass-independent isotope fractionation. Elements 5, 353-357 (2009).

52. J. M. Kraus, P. P. Gibson, D. M. Walters, M. A. Mills, Riparian spiders as sentinels of polychlorinated biphenyl contamination across heterogeneous aquatic ecosystems. Environ. Toxicol. Chem. 36, 1278-1286 (2017).

53. D. M. Walters, R. R. Otter, J. M. Kraus, M. A. Mills, Riparian spiders indicate the magnitude and sources of polychlorinated biphenyl contamination at a large contaminated sediment site. Environ. Toxicol. Chem. 37, 2467-2474 (2018).

54. IPBES, "Summary for policymakers of the assessment report on land degradation and restoration of the Intergovernmental Science-Policy Platform on Biodiversity and Ecosystem Services”, R. Scholes, L. Montanarella, A. Brainich, N. Barger, B. ten Brink, M. Cantele, B. Erasmus, J. Fisher, T. Gardner, T. G. Holland, F. Kohler, J. S. Kotiaho, G. Von Maltitz, G. 
Nangendo, R. Pandit, J. Parrotta, M.D. Potts, S. Prince, M. Sankaran and L. Willemen, Eds., IPBES Secretariat, Bonn, Germany, (2018).

55. T. Watari, et al., Total material requirement for the global energy transition to 2050: A focus on transport and electricity. Resour. Conserv. Recycl. 148, 91-103 (2019).

56. C. Banza Lubaba Nkulu, et al., Sustainability of artisanal mining of cobalt in DR Congo. Nat. Sustain. 1, 495-504 (2018).

57. G. Harper, et al., Recycling lithium-ion batteries from electric vehicles. Nature 575, 75-86 (2019).

58. D. M. Post, Using stable isotopes to estimate trophic position: Models, methods, and assumptions. Ecology 83, 703-718 (2002).

59. D. M. Walters, K. M. Fritz, R. R. Otter, The dark side of subsidies: Adult stream insects export organic contaminants to riparian predators. Ecol. Appl. 18, 1835-1841 (2008).

60. R. R. Otter, M. Hayden, T. Mathews, A. Fortner, F. C. Bailey, The use of tetragnathid spiders as bioindicators of metal exposure at a coal ASH spill site. Environ. Toxicol. Chem. 32, 2065-2068 (2013).

61. S. L. Speir, et al., Methyl mercury and stable isotopes of nitrogen reveal that a terrestrial spider has a diet of emergent aquatic insects. Environ. Toxicol. Chem. 33, 2506-2509 (2014).

62. D. M. Walters, M. A. Mills, K. M. Fritz, D. F. Raikow, Spider-mediated flux of PCBs from contaminated sediments to terrestrial ecosystems and potential risks to arachnivorous birds. Environ. Sci. Technol. 44, 2849-2856 (2010).

63. B. Wyn, K. A. Kidd, N. M. Burgess, R. Allen Curry, Mercury biomagnification in the food webs of acidic lakes in Kejimkujik National Park and National Historic Site, Nova Scotia. Can. J. Fish. Aquat. Sci. 66, 1532-1545 (2009).

64. U.S. EPA, "Method 7473 (SW-846): Mercury in Solids and Solutions by Thermal Decomposition, Amalgamation, and Atomic Absorption Spectrophotometry," Washington, DC, (1998).

65. K. A. Kidd, R. H. Hesslein, R. J. P. Fudge, K. A. Hallard, "The Influence of Trophic Level as Measured by $\delta 15 \mathrm{~N}$ on Mercury Concentrations in Freshwater Organisms" in Mercury as a Global Pollutant: Proceedings of the Third International Conference Held in Whistler, British Columbia, July 10--14, 1994, D. B. Porcella, J. W. Huckabee, B. Wheatley, Eds. (Springer Netherlands, 1995), pp. 1011-1015.

66. M. G. Clayden, L. M. Arsenault, K. A. Kidd, N. J. O’Driscoll, M. L. Mallory, Mercury bioaccumulation and biomagnification in a small Arctic polynya ecosystem. Sci. Total Environ. 509-510, 206-215 (2015).

67. T. Kidd, Karen A., Clayden, M., Jardine, Bioaccumulation and Biomagnification of mercury through food webs. (Wiley, 2012).

68. L. C. Chasar, B. C. Scudder, A. R. Stewart, A. H. Bell, G. R. Aiken, Mercury cycling in stream ecosystems. 3. Trophic dynamics and methylmercury bioaccumulation. Environ. Sci. Technol. 43, 2733-2739 (2009).

69. T. D. Jardine, K. A. Kidd, A. T. Fisk, Applications, considerations, and sources of uncertainty when using stable isotope analysis in ecotoxicology. Environ. Sci. Technol. 40, 7501-7511 (2006).

70. R Core Team, RStudio: Integrated Development for R, RStudio, PBC, Boston, MA URL http://www.rstudio.com/, (2020).

71. D. Bates, M. Mächler, B. M. Bolker, S. C. Walker, Fitting linear mixed-effects models using lme4. J. Stat. Softw. 67, (2015).

\section{Acknowledgments}


The authors would like to thank A. Rivas, D. Grovas Sala, M. Apaza, M. Macedo, S. Antoni Delgado, E. Chirinos, C. Vega, M. McNeice, W. Mendoza, S. Espinoza, D. Wolfe, and N. Szponar for assistance with fieldwork in Madre de Dios. A special thanks to the entire staff at the Centro de Innovación Científica Amazónica (CINCIA), especially J. Alferez Flores, J. AraujoFlores, J.C. Caballero, and M. Pillaca, who all provided invaluable support and guidance to JDL. In addition, the park rangers at Puesto Control La Torre and SERNANP Office were indispensable in their logistical support in the field. L.E. Fernandez at the Carnegie Institute for Global Ecology kindly provided assistance and access to laboratory space for mercury analysis. T. Dawson and S. Mambelli at the Center for Stable Isotope Biogeochemistry provided guidance, support, and access to facilities for processing stable isotope samples. F. Figuereido assisted with statistical analyses. We would also like to thank ME Power for helpful comments in the process of planning, executing, and writing up this research. JDL was supported by an NSF graduate research fellowship and research grants from the Tinker Foundation, Oliver Layman Fund, and Resh Family Fund.

\section{Author Contributions}

J.D.L., A.R., and M.D.P designed research; J.D.L performed research; J.D.L analyzed data; and J.D.L, A.R., and M.D.P wrote the paper. 


\section{Figures and Tables}

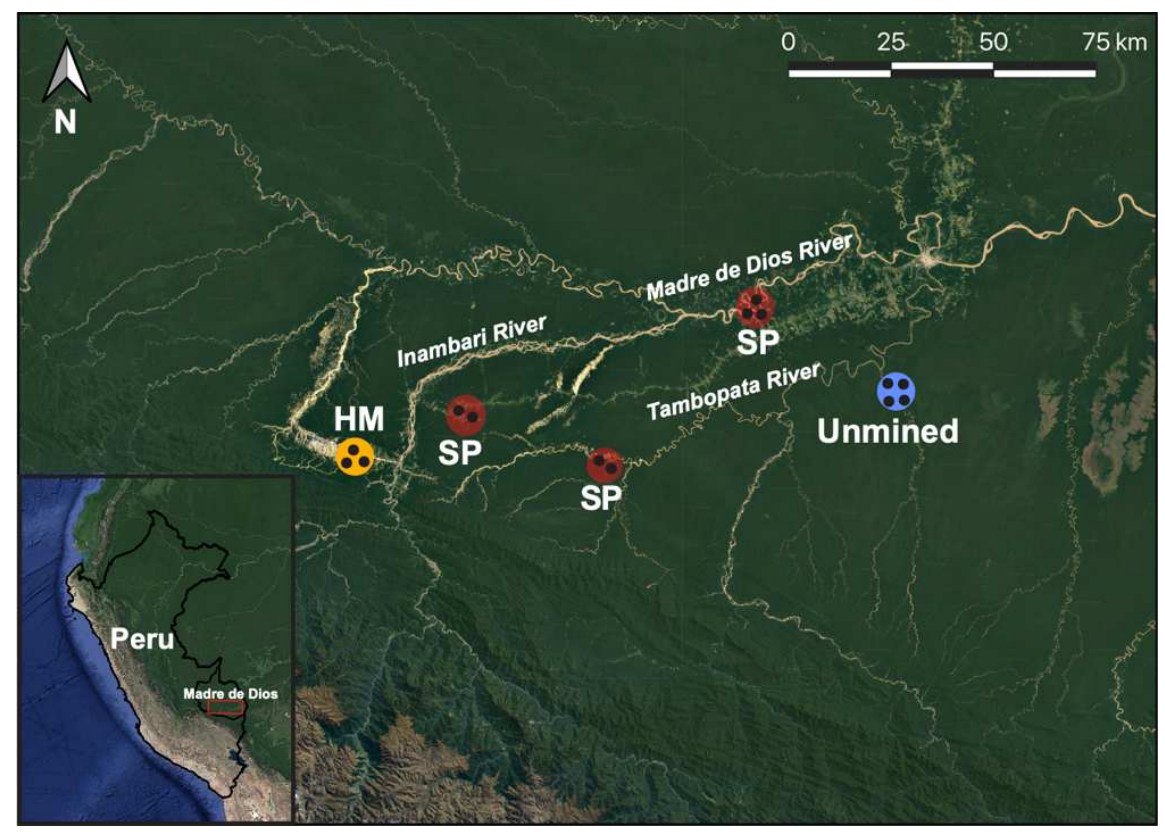

Figure 1. Map of study region showing approximate sampling locations and number of mines sampled (black dots) by type of machinery used in gold production: suction-pump based (SP) or heavy machinery $(\mathrm{HM})$, and one unmined site. 

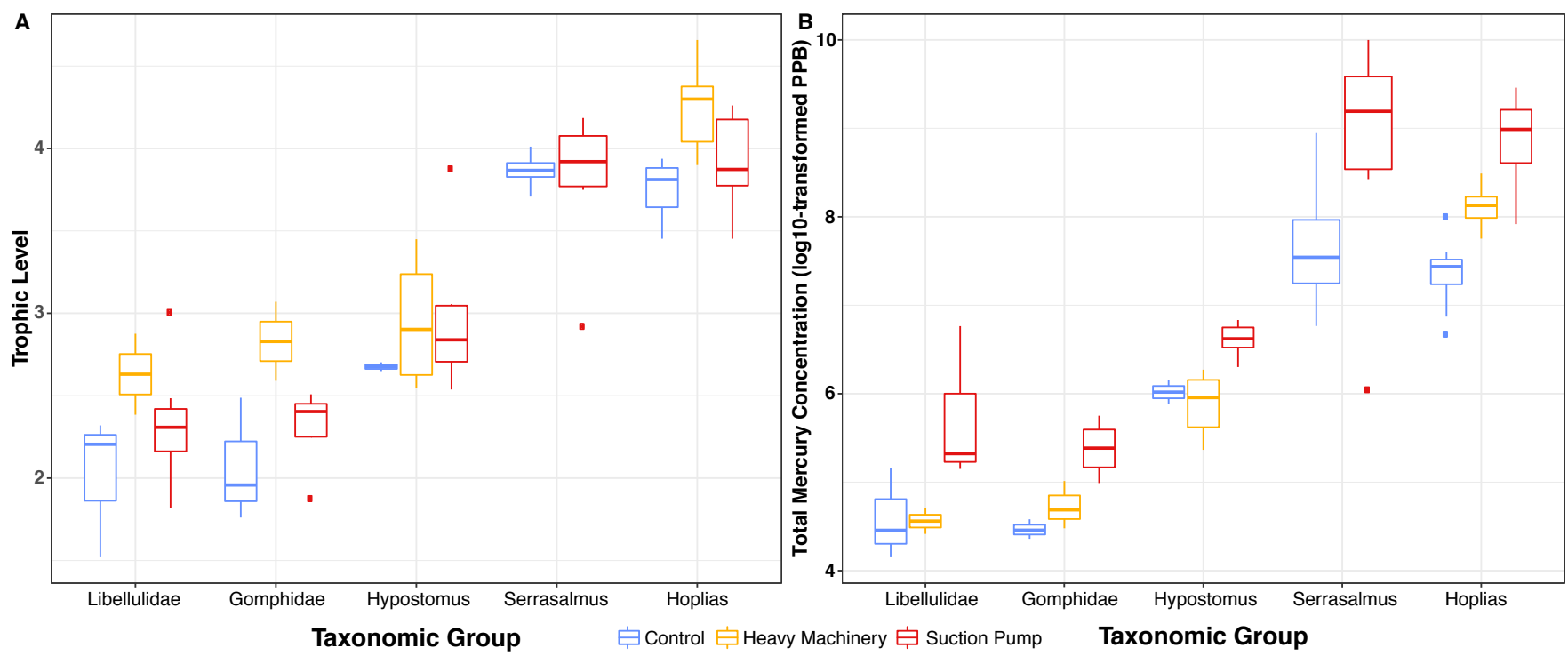

Figure 2. A. Differences in trophic level (calculated from $\delta 15 \mathrm{~N}$, see methods for more details) of taxa varied consistently across sites worked with different extraction technologies and reference oxbow lakes. B. Bioaccumulation of total inorganic mercury across sites worked with different extraction technologies. Taxonomic groups organized by increasing trophic level. 


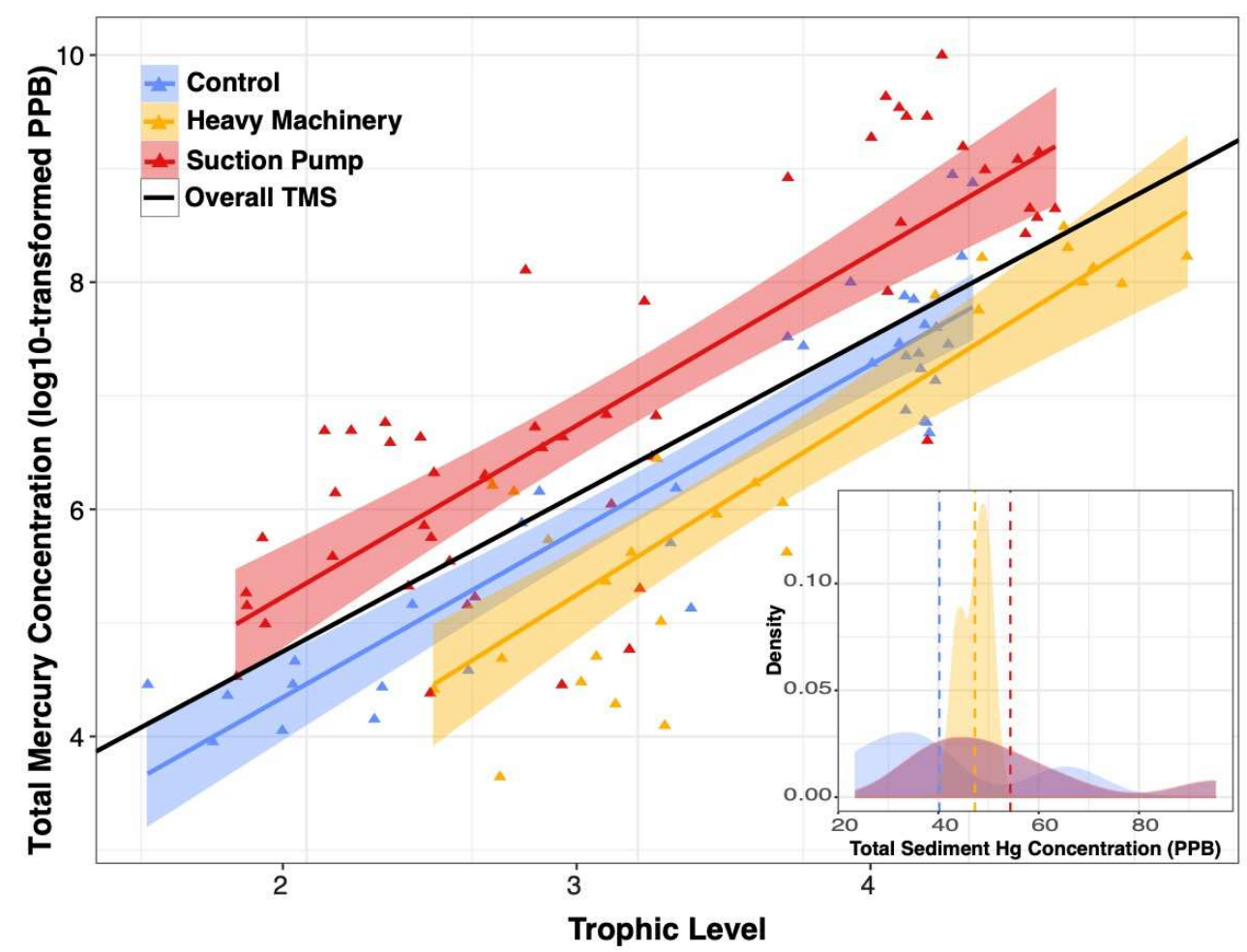

Figure 3. Trophic magnification slope (TMS) estimates overall (black line), and by type of extraction technology used (colored lines). Lines represent least squares estimate of the linear regression of total mercury concentration of biota against trophic level of taxa (calculated using $\delta 15 \mathrm{~N}$ estimates corrected using $\delta 15 \mathrm{~N}$ of a baseline consumer - see methods), with one standard error in slope estimate represented by shading. Inset - density plot of total sediment mercury concentration (PPB) by type of extraction technology. Dashed lines represent the mean total sediment mercury concentration across pits that differ in extraction technology. 


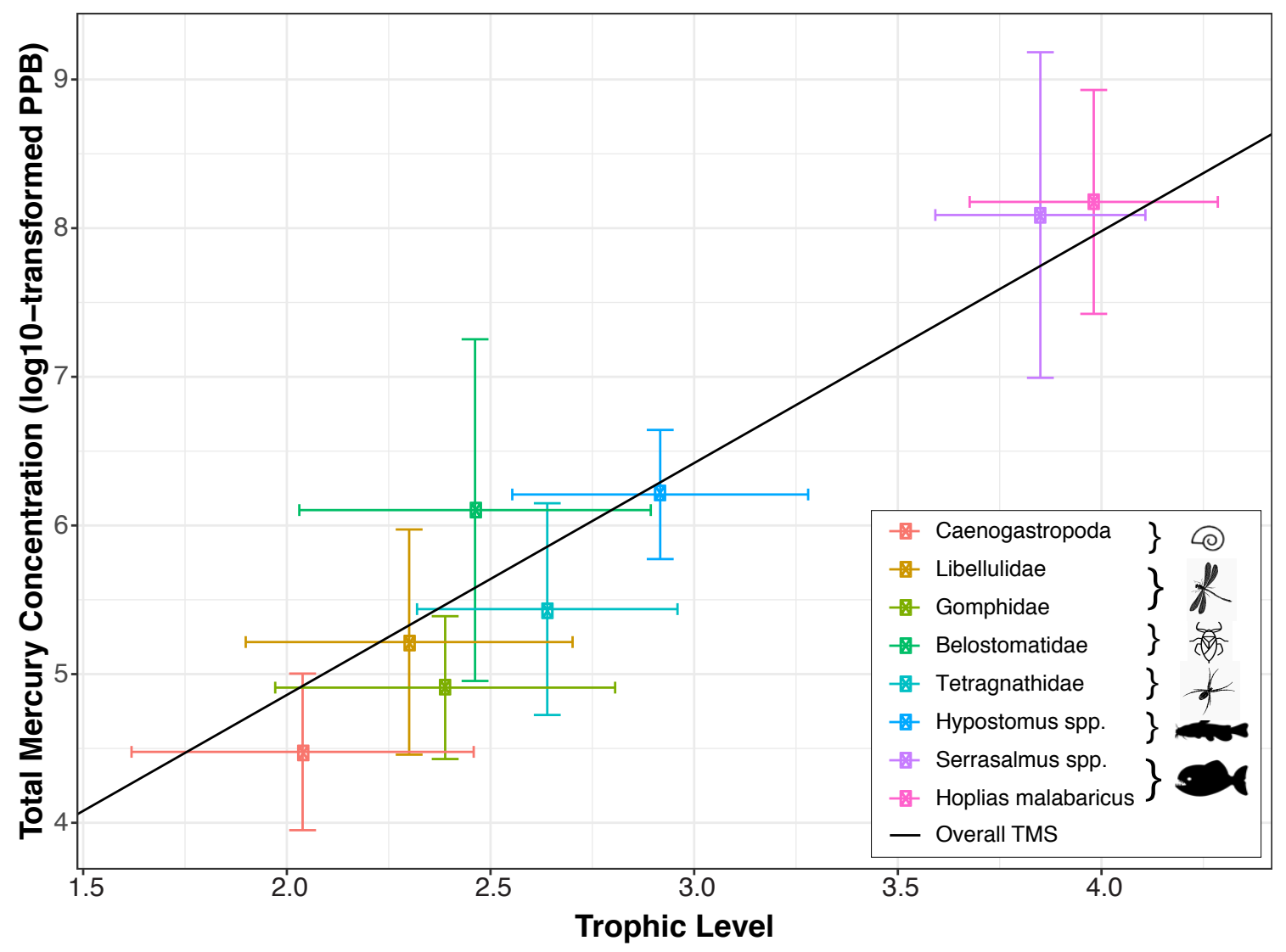

Figure 4. Mercury biomagnification by aquatic and terrestrial taxa sampled. Data points represent the mean trophic level and $\log _{10}$ transformed THg concentration \pm 1 S.E. for each taxonomic group sampled across all sites. Black line represents the least squares estimate of the trophic magnification slope calculated from linear regression of total mercury concentration in biota against estimated trophic level of taxa (calculated from $\delta 15 \mathrm{~N}$ concentrations corrected by baseline consumer $\delta 15 \mathrm{~N}$ - see methods). 
Table 1. Evaluation and comparison of linear mixed effects models: 1) restricted model including fixed effects accounting for taxonomic groups (Taxa), extraction technology (Tech), trophic position (Trophic Position), and a random effect of pit identity (1|Pit.ID), 2) model 1 plus a fixed effect of mercury loading (THgSed) in pits, 3) model 1 plus interaction between trophic position and extraction technology (1|Trophic Position:Tech), 4) model 3 plus the addition of mercury loading fixed effect.

\begin{tabular}{|c|c|c|c|c|c|}
\hline No. & Model & $\begin{array}{l}\text { Residual } \\
\text { Deviance }\end{array}$ & $\begin{array}{l}\text { Residual } \\
\text { df }\end{array}$ & BIC & $\begin{array}{c}\text { Log } \\
\text { Likelihood }\end{array}$ \\
\hline 1 & Taxa + Tech + Trophic Position + (1IPit.ID) & 473 & 15 & 559 & -236 \\
\hline 2 & $\begin{array}{l}\text { Taxa }+ \text { Tech }+ \text { Trophic Position }+ \text { THgSed }+ \\
\text { (1IPit.ID) }\end{array}$ & 469 & 16 & 561 & -234 \\
\hline 3 & $\begin{array}{l}\text { Taxa + Tech + Trophic Position + (1lPit.ID) + } \\
\text { (1/Trophic Position:Tech) }\end{array}$ & -210 & 16 & -119 & 105 \\
\hline 4 & $\begin{array}{l}\text { Taxa }+ \text { Tech + Trophic Position }+ \text { THgSed }+ \\
\text { (1IPit.ID) + (1ITrophic Position:Tech) }\end{array}$ & -216 & 17 & -119 & 108 \\
\hline
\end{tabular}




\section{Figures}

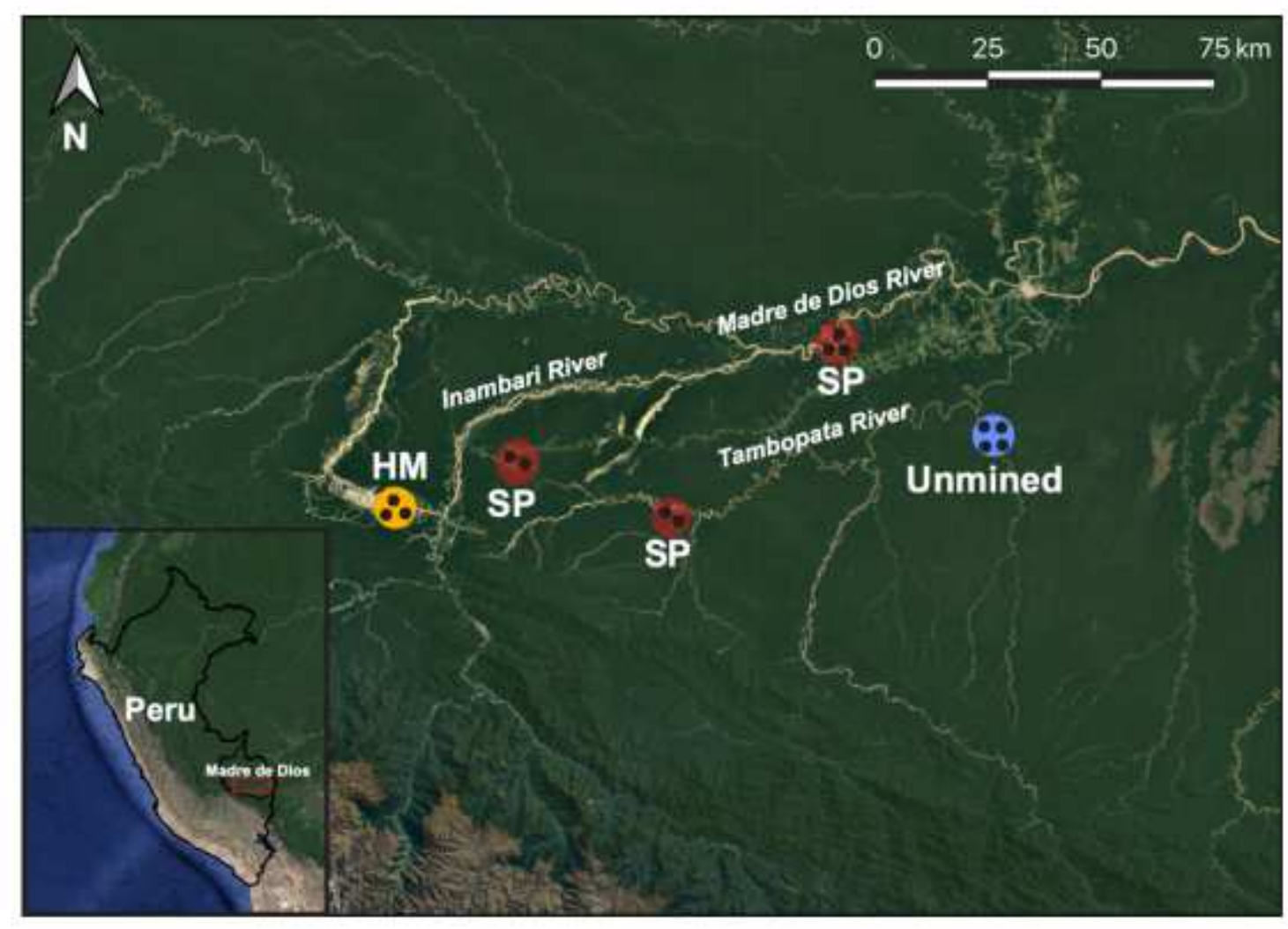

\section{Figure 1}

Map of study region showing approximate sampling locations and number of mines sampled (black dots) by type of machinery used in gold production: suction-pump based (SP) or heavy machinery (HM), and one unmined site.
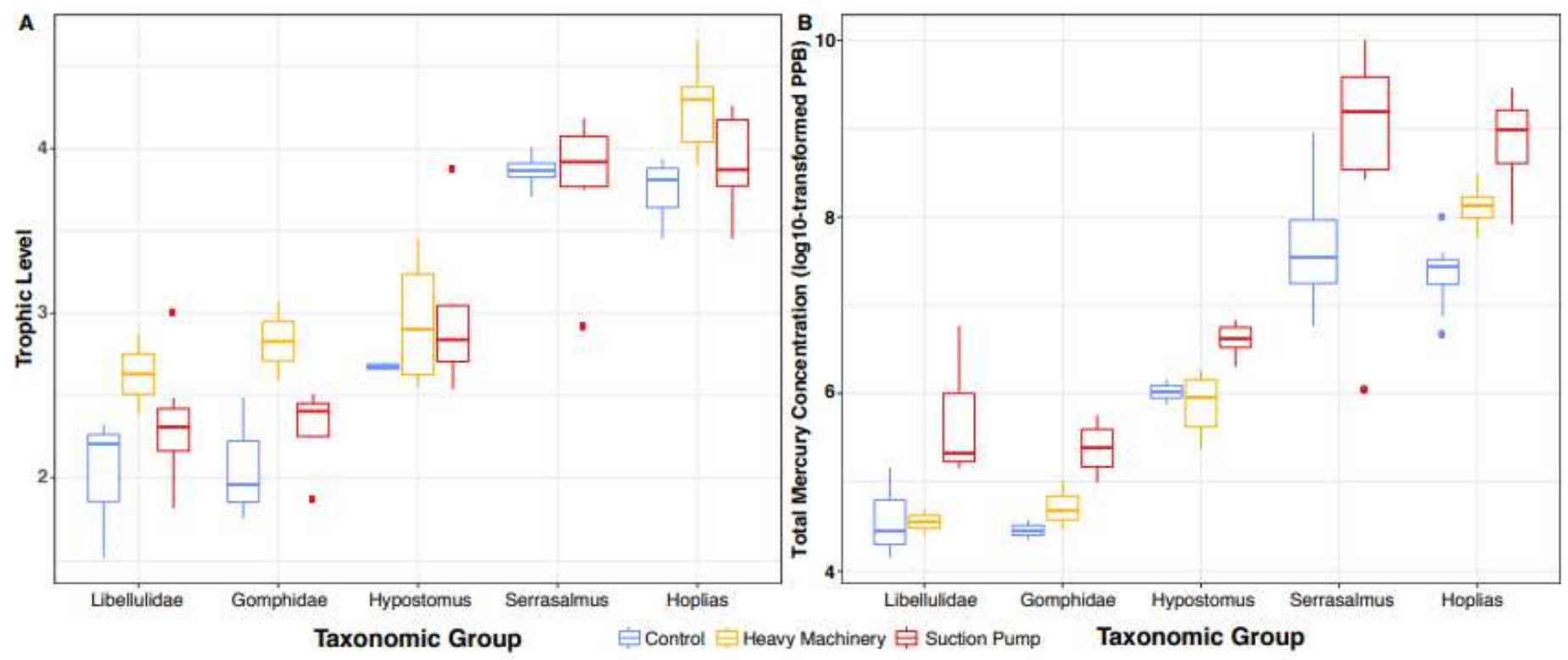
Figure 2

A. Differences in trophic level (calculated from $\delta 15 \mathrm{~N}$, see methods for more details) of taxa varied consistently across sites worked with different extraction technologies and reference oxbow lakes. B. Bioaccumulation of total inorganic mercury across sites worked with different extraction technologies. Taxonomic groups organized by increasing trophic level.

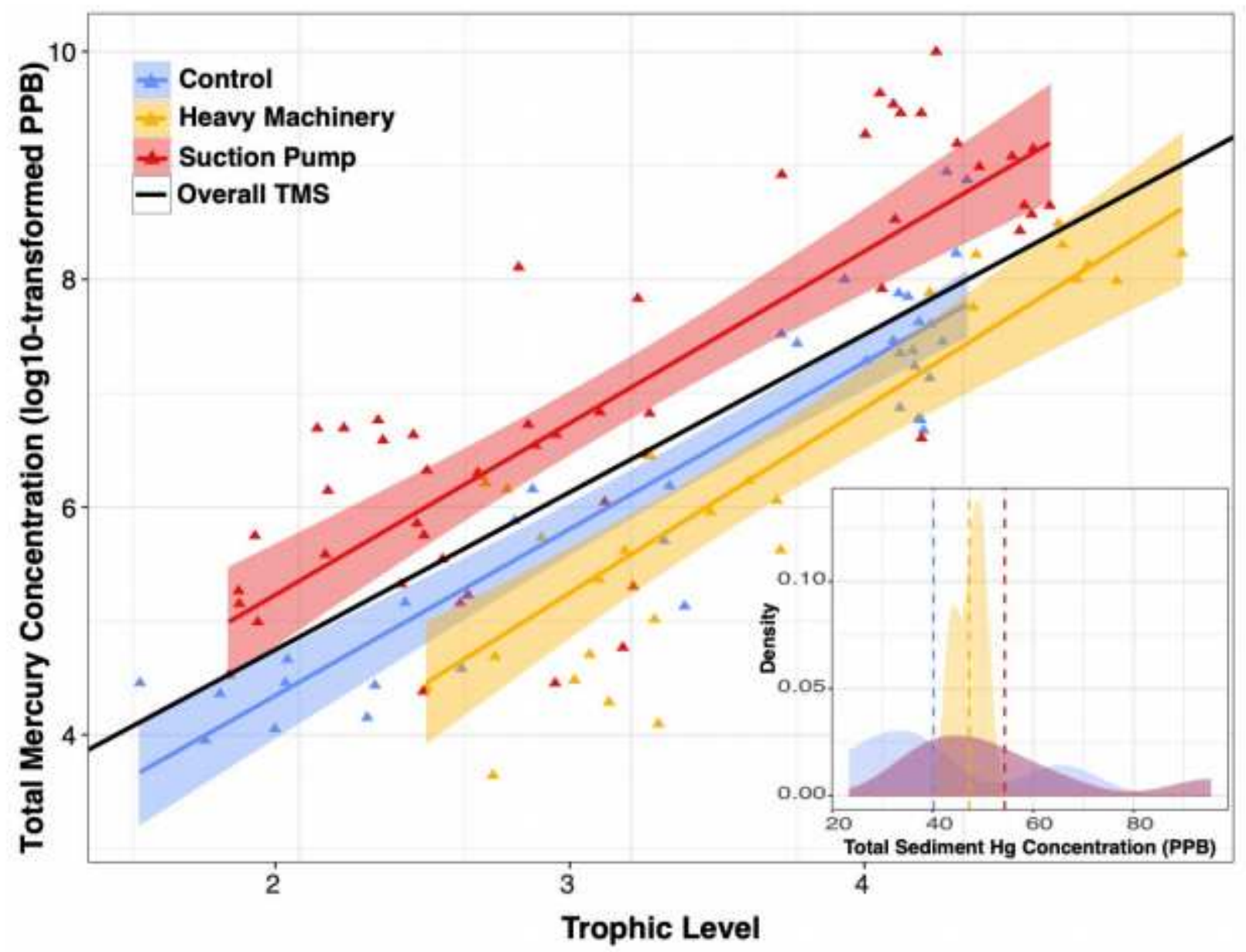

\section{Figure 3}

Trophic magnification slope (TMS) estimates overall (black line), and by type of extraction technology used (colored lines). Lines represent least squares estimate of the linear regression of total mercury concentration of biota against trophic level of taxa (calculated using $\delta 15 \mathrm{~N}$ estimates corrected using $\delta 15 \mathrm{~N}$ of a baseline consumer - see methods), with one standard error in slope estimate represented by shading. Inset - density plot of total sediment mercury concentration (PPB) by type of extraction technology. Dashed lines represent the mean total sediment mercury concentration across pits that differ in extraction technology. 


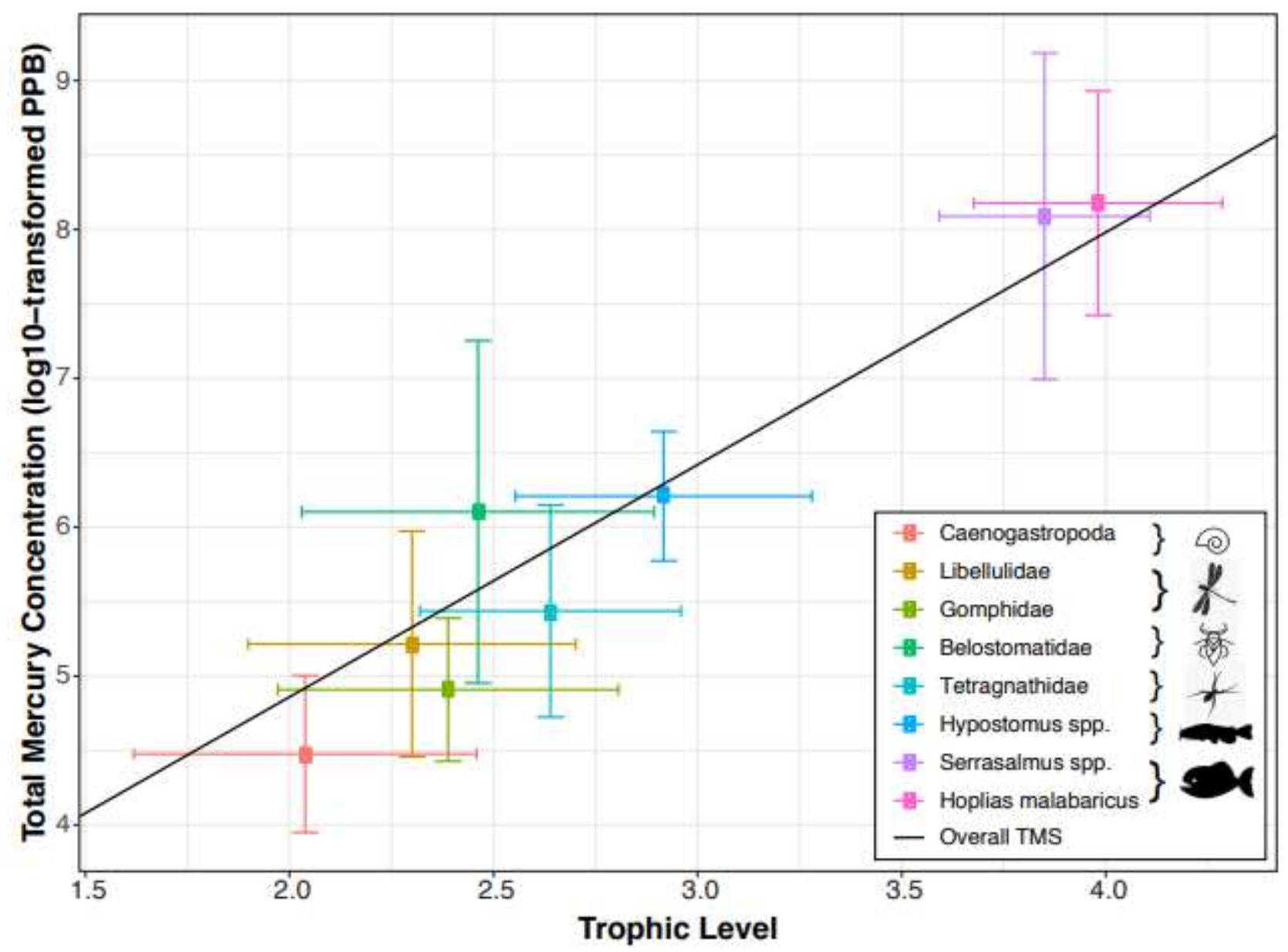

Figure 4

Mercury biomagnification by aquatic and terrestrial taxa sampled. Data points represent the mean trophic level and log10 transformed THg concentration \pm 1 S.E. for each taxonomic group sampled across all sites. Black line represents the least squares estimate of the trophic magnification slope calculated from linear regression of total mercury concentration in biota against estimated trophic level of taxa (calculated from $\delta 15 \mathrm{~N}$ concentrations corrected by baseline consumer $\delta 15 \mathrm{~N}$ - see methods).

\section{Supplementary Files}

This is a list of supplementary files associated with this preprint. Click to download.

- CoProductionSupplemental.pdf 